\title{
OCHO AÑOS DE TRIBUNAL DEL JURADO
}

\author{
JOSÉ ÁNGEL MARÍN GÁMEZ \\ ProfesorTitular de Derecho Constitucional \\ Universidad de Jaén
}




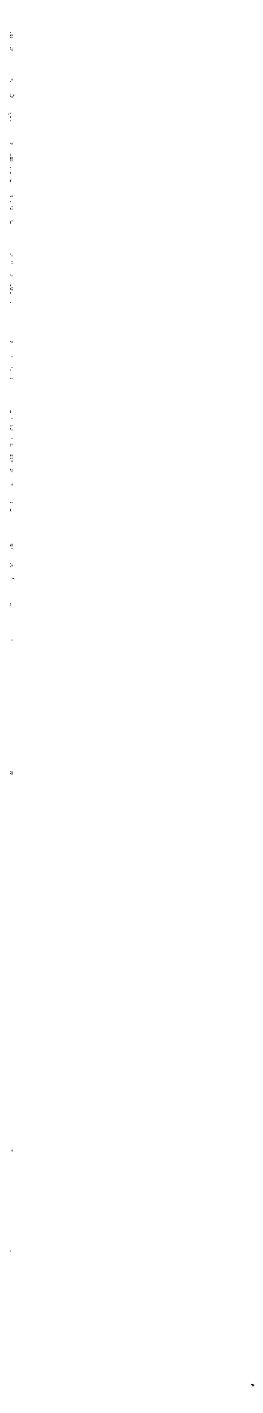

\section{.}




\title{
OCHO AÑOS DE TRIBUNAL DEL JURADO
}

\author{
POR \\ JOSÉ ÁNGEL MARÍN GÁMEZ \\ ProfesorTitular de Derecho Constitucional \\ Universidad de Jaén
}

Pulsando buen número de análisis y comentarios, algunos apasionados, otros apresurados y todos -incluido éste- discutibles, sobre la funcionalidad $y$ disfunciones del Jurado que rige actualmente en España, uno se encuentra con la percepción sencilla y preliminar de que existe cierta inquietud y hasta desazón cuando no abierto pesimismo entre los vinculados a la Administración de Justicia que son interrogados sobre una cuestión como ésta. El hecho de que sea cual sea el foro de debate no deje de ser candente la temática sobre el Jurado, institución formulada desde 1978 en la Constitución española y que no obstante tardó en hacerse presente hasta su regulación más de tres lustros después, concretamente mediante la Ley Orgánica 5/1995 (v R. D. 1398/1995, de 4 de agosto, por el que se regula el sorteo para la formación de las listas de candidatos a jurados), ya suscita el interés de los estudiosos e iniciados en el tema. Desde aqui, hoy prestaremos renovada atención al mandato constitucional que dio lugar a la promulgación de la Ley Orgánica 5/1995, de 22 de mayo, del Tribunal del Jurado (BOE núm. 122, de 23 de mayo), texto luego modificado por la Ley Orgánica 8/1995, de 16 de noviembre (BOE núm. 275, de 17 de noviembre).

No se falta a la realidad cuando se dice que no fue un alumbramiento pacífico el de esta Ley; ni pacífico está siendo su desarrollo, 
añadiríamos desde aquí a la anterior constatación. Con todo, la impresión de larvado pesimismo, como decimos de cierta frustración o impotencia ante la figura del Tribunal del Jurado regulado y vigente hoy en España, merecería un tratamiento sociológico, o quizá psicológico, que aquí naturalmente se nos escapa. Lo que parece innegable es que ese pesimismo o desaliento apenas disimulado cuando se habla entre juristas del Jurado, nos pone sobre las pistas de un pensamiento sacralizador de la justicia bastante extendido entre legos y también entre iniciados $y$ que suscita muchas otras interrogaciones, si cabe más preocupantes después de veinticinco años de Estado de Derecho y Constitución. Cierto es que en los dos primeros años de vigencia de la Ley del Tribunal del Jurado ha habido motivos para la polémica, al menos en una doble dirección. Por una parte, rescatando un tracto histórico de perplejidad colectiva ante veredictos sorprendentes y sorpresivos. (Recordemos en este extremo el que el gran público ha conocido como "caso Otegui». En el mismo tuvo lugar un veredicto sorprendente que seguramente a nadie sorprendió dadas las circunstancias y el contexto socio-político en el que se habrían de producir las consideraciones y valoraciones de los hechos enjuiciados. Pero sigamos refrescando un tanto la memoria: el proceso Otegui, celebrado ante la Audiencia Provincial de Guipúzcoa, proceso que terminó con la absolución del inculpado que de propia mano y meses antes había acabado con la vida de dos policías autónomos vascos. El veredicto absolutorio emitido por los jueces legos provocó gran número de comentarios e igual cantidad de preocupaciones. Lo paradójico de la resolución que la justicia popular ofrecía en el renombrado caso, evidentemente, puso una vez más en solfa la normalidad de la institución y oscureció aún más el siempre sombrio panorama del Jurado en España). De otra parte, la misma problemática ha obligado a los juristas a un esfuerzo interpretativo en la búsqueda de claves que permitieran superar los problemas latentes en el cuerpo legal, generando enfrentamientos doctrinales en los que el ámbito del debate trascendía la discusión en torno al modelo de Jurado implantado, para incidir y cebarse en la existencia misma de esta institución.

Tengamos presente también que el propio Consejo General del Poder Judicial, en su preceptivo informe al que fue Anteproyecto de Ley del Jurado, mostró claramente sus preferencias por el escabinado o jurado mixto frente al jurado puro o anglosajón. En este tramo todavía preliminar de la exposición que presento al amable lector, pueden resultar cuando menos curiosos los pareceres expresados entonces por Pascual Sala, a la sazón cabeza del Consejo General del Poder Judicial, y también las opiniones del decano del Colegio de Abogados 
de Madrid, Luis Martí Mingarro. El representante de la judicatura declaraba a la fatídica pregunta de por quién preferiría ser juzgado, si por un tribunal técnico o por jueces legos, que usi fuera inocente por jueces técnicos, y si fuera culpable, por un Jurado". El letrado por su parte se limitaba a señalar en octubre de 1995 que ante la entrada en vigor del Jurado el colectivo de la abogacía se planteaba una expectación preocupada, recelosa y reticente y que uesa ley no había sido reclamada desde la abogacía".

Nosotros el planteamiento de partida quisiéramos hacerlo arrancar de un conjunto de premisas ordinales y omnipresentes en toda labor y decisión jurisdiccional. Estos postulados básicos, seguramente obvios, tienen mucho que ver con la consistencia e integridad de los quehaceres propios de todo juzgador, dado que en general puede afirmarse que quienes antes de realizar un acto de autoridad y poder en el que nos les va ningún provecho, interés o pasión personal, han de meditar, han de explorar sus implicaciones y consecuencias, y se ven inclinados - feliz inclinación-casi sin querer a convertirse en valladares contra el apresuramiento, el atropello y la vejación inmotivados. Quienes así operan se ven inclinados, por tanto, a convertirse en garantes ciertos de la inocencia del inocente, en una palabra, en defensores de la libertad constitucional colectiva y de los derechos individuales básicos.

En tiempos en los que aletea permanentemente la reivindicación por una justicia firme e independiente (no hay más que ver la última edición del Libro Blanco de la Justicia), y en fechas en las que permanecen impenitentes buena parte de las injerencias del poder ejecutivo sobre los aparatos y los agentes de la justicia. En tiempos en que afloran las reticencias de algún poder legislativo autonómico (mesa de la Cámara vasca) frente a los pronunciamientos concluyentes del poder prismático y cenital del Tribunal Supremo; lo que dicho sea de paso supone, de un lado, poner en un brete a la cúspide del organigrama judicial, $y$, de otro lado, lacera sobre cuestiones tan graves como irredentas que conciernen a la estructura territorial del Estado. En tiempos en los que algunos diputados autonómicos se empeñan en sisar la voluntad política de sus electores transitando por las escondidas sendas del transfugismo político (Asamblea de Madrid), a la vez que ofrecen también y de paso un espectáculo parlamentario desde todo ángulo poco edificante. En este contexto algo voraginoso en que la Constitución española de 1978 cumple veinticinco años, creo que conviene reflexionar sobre la fe que los ciudadanos, en general, y justiciables, en particular, tienen en torno a las virtudes y cualidades de los jueces legos a la hora de administrar justicia conforme al artículo 125 
de la Constitución. Y también, por qué no decirlo, conviene reflexionar sobre los postulados doctrinales sentados al respecto.

Soy de la opinión de que las peticiones y propuestas participativas deben ser una inquietud latente en toda sociedad que tenga su base en la confianza de la que surge la democracia. En mi libro Elementos para una revisión crítica del Jurado en España (UNED, 1997), quedó plasmada una idea que sin duda incide en la dirección apuntada. Se trataba y trata del siguiente postulado: la inquietud por los asuntos públicos y las posibilidades reales de participar en la cosa pública se refuerzan mutuamente, es decir, donde el interés del pueblo hace patente su voluntad transitiva se activan los resortes, mecanismos e instrumentos de participación, y donde estos cauces participativos funcionan razonablemente aumenta el interés y la inquietud de la ciudadanía por los asuntos públicos. Con lo cual el círculo de la transitividad, el sentimiento y la lealtad constitucional se cierra y adquiere una cadencia democrática que me atrevo a calificar de verdaderamente encomiable. Por ello no debe extrañar que el argumento de la participación del pueblo en la Administración de Justicia haya sido objeto de programas, proyectos y debates políticos a lo largo de la historia. Así lo demuestra el hecho de que este asunto estuviera siempre presente en los planteamientos de partidos y tendencias de corte liberal o, del mismo modo, que la historia de nuestro Jurado esté caracterizada por las fluctuaciones de la política nacional, instaurándose en épocas de regímenes democráticos, para quedar suprimido o restringido en los períodos marcados por la égida autocrática. Períodos de égida autocrática en los que se extendían e imponían retrocesos de las libertades públicas y, por consiguiente, en este instrumento de participación ciudadana en los asuntos de general preocupación tanto para los ciudadanos, las autoridades y las instituciones. Asi, es incontestable que cada período de libertad ha significado en nuestro pais la consagración delTribunal del Jurado, y buen ejemplo de ello son las Constituciones de 1812, 1837, 1869 y 1931. Otra cosa es referirnos al éxito de la institución en cada momento histórico. De hecho la experiencia histórica que hemos acumulado al respecto no se presenta excesivamente afortunada; hasta se puede hablar de experiencia fallida en los precedentes legislativos de 1888 y 1933. Buceando en la memoria histórica es curioso reseñar algunos aspectos relacionados con el tema y que no dejaron de tener reflejo en la Memoria de la Fiscalía General de la República de 1935. En ella los fiscales de las Audiencias elevan a la Presidencia de la II República un conjunto de pareceres poco complacientes con la institución y despachados con expresiones del siguiente tenor: institución ignorante, inculta y sobornable..., punto 
negro de la justicia..., venalidad en los veredictos..., apaño y miedo en los jurados. Y algunas otras (des)calificaciones del mismo porte que me ahorro por el momento.

Pese a todo, ya en los tiempos actuales dicha constante histórica vuelve a estar presente tanto constitucional como legalmente. $Y$ se trasluce en la participación de los ciudadanos en la Administración de Justicia a través del Jurado, propiciada por el artículo 125 del Texto Básico. Constante normativa que podremos leer concatenada con los artículos 23.1 y 24.2 del mismo Cuerpo normativo y sostenida incluso desde el Preámbulo constitucional. Uno de los postulados de partida antes aludidos a los que quisiera apelar y al que convendría aplicar maniobras de resucitación rápida e inmediata, tiene apoyo en la convicción roussoniana que sostiene que basta conceder a un hombre o a un grupo de personas que se consideren tales (como es el caso del colegium singular formado por ciudadanos-jurados), la calma suficiente en un clima de objetividad y desinterés, y suministrar a semejante colegio ciudadano los datos veraces procedentes de los diferentes puntos de vista puestos en juego en la litis criminal, para que la razón se abra camino, para que la voluntad general rectamente entendida, o sea la ley y la justicia constitucionalmente interpretada por el parecer de la mayoría, encuentren el punto de equilibrio más razonable en la solución de un conflicto concreto generado por una conducta antisocial que deviene también antijurídica en dicho litigio.

Por otro lado, el contexto general de la España de 1995 en el que se procede al envite legislativo que alumbra la institución del Jurado, es neta y nítidamente de impronta constitucional. Es decir, se da en el ámbito expansivo de los derechos ciudadanos y su oferta supone el enriquecimiento del elenco de facultades y obligaciones que integran el estatuto de ciudadanía que casa con el primordial objetivo propuesto por nuestra Carta Magna de construir una sociedad democrática avanzada. Qué se puede objetar desde dicho entronque a una institución constitucionalmente así suscitada, que lubrica e incide en los modos de relacionarse la sociedad civil con los poderes públicos $y$, en particular, con la Administración de Justicia. Esta es necesariamente la longitud de onda en la que tenemos que emitir el presente trabajo - más aún cuando estamos celebrando un cuarto de siglo de vida de la Constitución del 1978-, porque es más que probable que tal conjunción de factores nos facilite algunas de las claves solutorias del problema de la legitimación del derecho y de la justicia que a partir de entonces se están dando sobre nuestro suelo. El emplazamiento y sistemática del artículo 125 de la Constitución es inequívoco e ilustrativo al respecto. De una parte fuerza una vuelta de tuerca en las vivencias y expectati- 
vas de participación popular en los asuntos públicos, $y$, por otra parte, los matices constitucionales que podemos leer en el artículo 125 sintonizan con una demanda social de cambio en los modos de administrar justicia en España. Lo que nos reafirma en la opinión favorable a implantar el Tribunal de Jurado en la modalidad seleccionada por el legislador democrático para nuestro ordenamiento jurídico.

Ahora bien, del mismo modo que aquí aparece franca la apuesta juradista, no conviene acudir a ella como panacea categórica. Cierto es que la participación popular en la Administración de Justicia representa un hito dentro del impulso democrático reverdecido en la realidad política y social española desde diciembre de 1978. De hecho son muchos los autores que afirman que es difícil encontrar un modelo de democracia avanzada sin contar con alguna versión más o menos tamizada de la participación del pueblo en la Administración de Justicia. De ahí colegimos sin demasiados artificios que la participación de los ciudadanos en labores jurisdiccionales es relevante para la propia democracia, si bien la identificación de una y otra es una operación indudablemente delicada, debido a que el solo hecho de que la institución permanezca inédita constitucional o legalmente no representa, por sí mismo, que estemos ante un orden o modelo democrático ochavado. Aunque, eso sí, tal carencia reguladora en los dos ámbitos (constitucional y legal) da idea de cierta capitidisminución en los cauces específicos con que el pueblo cuenta para terciar en uno de los poderes del Estado. Ahora bien, no es, sin más, de recibo que si fracasa o no se alumbra el Jurado en los textos normativos la democracia está llamada al fiasco.

Indefectiblemente tenemos que partir de la circunstancia de que el esquema político introducido por la Constitución de 1978, sin ser una maquinaria suiza - que no lo es-, funcionó razonablemente hasta 1995, fecha en que se incorpora el Tribunal del Jurado; $y$ del mismo modo produjo efectos positivos para nuestra sociedad con posterioridad a dicha fecha. En este orden lógico del sistema constitucional perfectible, en el que puede o no estar presente el Tribunal del Jurado, el magistrado Ruiz Vadillo ha considerado que "de ahí a pensar que sin Jurado, puro o mixto o escabinado, no hay democracia, hay un abismo". Esto lo decía Ruiz Vadillo en la Academia de Jurisprudencia y Legislación allá por 1988. En aquella fecha el artículo 125 de la Constitución estaba huérfano de desarrollo legislativo, pero ello no significaba que a la misma fecha nos faltara la democracia en España. Otra cosa, añadia Ruiz Vadillo y no le faltaba razón, hubiera sido la ausencia del sufragio universal en nuestro orden político y jurídico. No quiero dejar de señalar ahora una idea que plantearé al final de este tra- 
bajo, puesto que ha salido en el discurso que propongo sobre el Jurado el nombre del prestigioso juez. Me referiré escuetamente por el momento, emplazando al lector para los últimos tramos del texto que tiene entre sus manos, a que por lo general han sido magistrados del Tribunal Supremo como Ruiz Vadillo, Martín Pallín y otros los auténticos valedores de la institución en la alta instancia jurisdiccional, aun a costa de revocar y deshacer resoluciones procedentes de la sala de lo penal correspondiente de los respectivos Tribunales Superiores de Justicia de las diferentes Comunidades Autónomas. Quiero señalar con ello que elTribunal Supremo se ha erigido en restaurador cierto de los pronunciamientos $y$ veredictos emitidos por jurados competentes en el ámbito provincial de procedencia. Y ello ha sido así cuando tras la correlativa apelación ventilada ante elTribunal Superior de Justicia respectivo, el veredicto de los jueces legos había sido puesto en solfa por la propia instancia territorial.

A título ilustrativo y como ejemplo baste sólo citar el caso de la muerte violenta de Rocío Wanninkhof ocurrida en la costa malagueña, caso resuelto en primera instancia por un Jurado mediante veredicto de culpabilidad para la acusada perteneciente al entorno próximo de la fallecida: siete votos contra dos. El caso Wanninkhof dio lugar a una sentencia condenatoria por el delito de asesinato a quince años de prisión, sin embargo la Sala de lo Penal delTribunal Superior de Justicia de Andalucía anuló dicha sentencia del jurado popular correspondiente a la Audiencia Provincial de Málaga, ordenando repetir el juicio con distintos jueces legos.

En este mismo orden ilustrativo también puede ser traído a colación no sólo por lo que tiene de curioso y llamativo el caso ocurrido en el partido judicial de Linares (Jaén), caso en el que un hombre de mediana edad marido de la finada simuló la muerte accidental, supuestamente en un lance de tráfico, de su cónyuge. Tras el proceso penal el marido resultó condenado por un jurado popular en la Audiencia Provincial de Jaén a la pena de doce años y seis meses de prisión, veredicto que luego resultó anulado en la Sala de lo Civil y Penal correspondiente al Tribunal Superior de Justicia de Andalucía, con sede en Granada, sentencia emitida en apelación que, a su vez, quedó sin efecto tras el pronunciamiento abiertamente favorable al veredicto de los jurados dictada por la Sala Segunda de lo Penal del Tribunal Supremo. La sentencia que contenía el veredicto de los jueces populares jien- 
nenses es de veintiséis de abril de dos mil uno, y en su parte dispositiva condena al marido procesado como autor responsable de un delito de homicidio, con la agravante de parentesco, a la pena de doce años y seis meses de prisión y al pago de las costas generadas, y a que en concepto de responsable civil el mismo indemnice a los padres de la víctima en la cantidad de veinte millones de las antiguas pesetas. Dicha actuación penal del Jurado dio lugar al correspondiente rollo de apelación respecto de los autos originales de juicio penal seguidos ante el Tribunal del Jurado en el ámbito de la Audiencia Provincial de Jaén, y que conoció en audiencia pública la Sala Civil y de lo Penal del Tribunal Superior de Justicia de Andalucía, emitiendo en tal recurso su sentencia de once de julio de dos mil uno. Contra el criterio de los jueces populares, el Tribunal Superior de Justicia estimó el recurso de apelación interpuesto por el que había sido condenado en primera instancia en Jaén, revocando en consecuencia dicha sentencia $y$, en su lugar, absolvió libremente al marido acusado del homicidio de su esposa, declarando de oficio las costas procesales causadas en ambas instancias. Ello supuso que el primeramente condenado y luego absuelto fuera puesto inmediatamente en libertad. Las anteriores actuaciones dieron lugar al recurso de casación número 2649/2001 por infracción de precepto constitucional, de ley y quebrantamiento de forma, interpuesto por la acusación particular contra la sentencia antedicha delTribunal Superior de Justicia de Andalucía que estimaba, a su vez, el recurso de apelación planteado contra la sentencia de la Audiencia Provincial de Jaén. La sentencia dictada en casación es la número 2001/2002 delTribunal Supremo, de fecha veintiocho de noviembre de dos mil dos, cuya parte dispositiva contiene la declaración de que ha lugar al recurso de casación, por quebrantamiento de forma, interpuesto por la acusación particular contra la sentencia del Tribunal Superior de Justicia andaluz, casando y anulando la referida sentencia, con declaración de oficio de las costas procesales generadas. Los ejes de la argumentación esgrimida por la acusación particular (recurrente) en casación giraban en torno a la que ya podemos calificar como improcedente modificación de los hechos probados, operada por el Tribunal Superior de Justicia respecto de los declarados como tales por el Tribunal del Jurado jiennense. De modo que lo que en realidad hace el Tribunal territorial es apreciar de nuevo una prueba que no se había practicado a su presencia, sino ante los jueces legos, además de únicamente tener en cuenta tres de los múltiples indicios valorados por el Tribunal popular. Lo cierto e impecable jurídicamente es que tanto el Tribunal de casación como el de apelación en el caso del Tribunal del Jurado, deben comprobar no sólo la virtualidad de los medios de 
prueba aportados como de cargo por la acusación (pública o particular), sino que además en las distintas instancias los juzgadores deben corroborar la racionalidad del proceso valorativo efectuado por el Tribunal a quo. Ello no extraña a ningún observador del Derecho puesto que en el análisis criminal de la presunción de inocencia es fundamental la comprobación de la motivación sobre los hechos que se declaran probados y adquieren la categoria de resultancias fácticas jurídicamente relevantes de cara a una eventual condena. Este es un criterio compartido y coincidente tanto para el Tribunal Constitucional como para el Tribunal Supremo (SSTC 16, 58 y 165/1998, SSTC 28, 122 y 177/1999. Y concordantes SSTS 629 y 1009/1996, 621/1997, 1749/2000, $914 / 2001,399 / 2002$ y 2036/2002). Al hilo de lo expuesto y siempre con la finalidad de proscribir la arbitrariedad de toda decisión judicial, en la decisión del Tribunal Supremo 2001/2002 que nos está sirviendo como referencia última en el caso de marras enjuiciado por jurados en Jaén, la Sala Segunda de la Alta Instancia jurisdiccional argumenta que "cuando se trata de sentencias dictadas por el Tribunal del Jurado, no puede exigirse a los ciudadanos que lo integran el mismo grado de razonamiento intelectual y técnico que debe exigirse al juez profesional, y por ello la Ley Orgánica del Tribunal del Jurado sólo requiere en el artículo 61.1.d), la expresión de los elementos de convicción y una sucinta explicación de las razones por las que han declarado o rechazado declarar como probado unos determinados hechos, aspectos que deberán ser completados por el magistrado-presidente de conformidad con lo dispuesto en el artículo 70.2. Pero la exigencia de motivación, en cuanto elemento que permite la intelegibilidad y el control de la racionalidad de la decisión, no desaparece cuando se trata de una sentencia delTribunal del Jurado y por lo tanto, aunque no sea exhaustiva, debe ser suficiente para dar adecuada satisfacción a las necesidades que justifican su exigencia». En definitiva y por tratarse en el caso de la valoración de la prueba indiciaria aportada, el Tribunal Supremo está exigiendo también a los jueces legos que se apoyen en elementos de hecho y que éstos sean varios, acreditados y relacionados hasta el punto de reforzarse entre sí, de manera que el juicio de inferencia pueda considerarse razonable y que la sentencia que contenga el veredicto asi lo exprese. Creemos que es certera la apreciación del Supremo cuando reconoce las dificultades que la ley reconoce para plasmar de alguna forma la valoración de la prueba realizada por los jurados, dificultades que se incrementan cuando la prueba que se tiene en cuenta no es prueba directa sino prueba indiciaria. De modo que los jueces legos están obligados a sentar en su escueta explicación las bases de la prueba indiciaria, es decir, los indicios básicos que 
han tenido en cuenta como elementos de convicción, mientras que corresponde al magistrado-presidente, partiendo de la expresión en la sentencia de la motivación de los jurados, concretar la existencia de prueba de cargo mediante la constatación de los indicios y la razonada expresión de la inferencia en la sentencia que finalmente se dicte. Es cierto que pueden ser legión las dificultades para concretar la expresión de un proceso racional que no ha sido efectuado por quien redacta la sentencia, pero en el caso de la dictada a quo en la Audiencia Provincial de Jaén por el magistrado Aguirre Zamorano y que nos está sirviendo de parámetro ejemplificativo, éste sabe concitar tales aspectos y teóricas controversias. De ahí que el Tribunal Supremo no podía por menos que casar $y$ anular la decisión del Tribunal territorial andaluz, debido a que éste sobrepone su propio criterio al criterio rectamente elaborado por jurados en la Audiencia de Jaén, sobrepasando así los límites del control que procede realizar sobre la valoración de la prueba. Los juzgadores ad quem, tanto en casación como en apelación, cuando se trata de sentencias delTribunal del Jurado, deben constreñirse a efectuar un doble control. Uno, verificar la existencia y validez de la prueba de cargo practicada e incorporada al juicio oral de acuerdo con las reglas constitucionales y de legalidad ordinaria que disciplinan estos extremos. Dos, el juzgador que conoce del recurso debe limitarse a comprobar la racionalidad de la valoración que haya hecho de dicha prueba el juzgador de instancia. Y, por supuesto, no entrar en ejercicios sobre valoraciones relativas a la percepción sensorial de la prueba so pretexto de suplantar al juzgador que efectivamente ha dispuesto de la inmediación y evidenciado la racionalidad de su propio proceso valorativo. Fue esto precisamente lo que hizo el Tribunal Superior de Justicia en el caso que analizamos: sustituyó el criterio valorativo del Tribunal sentenciador por el suyo propio como Tribunal revisor. Resulta patente que el Tribunal Superior de Justicia dirige su actividad a comprobar si en la sentencia recurrida se contiene un razonamiento que responda a las reglas de la lógica y de la experiencia, verificando la existencia de prueba sobre extremos fácticos y, naturalmente, llegando a la conclusión de su inexistencia. Pero tal como indicó el recurrente en casación: le atribuye, sin embargo, consecuencias que no se siguen de esa comprobación. Así la declaración de hechos probados encuentra su origen en una propuesta no adecuada del objeto del veredicto al someter a la consideración de los jurados dos proposiciones contrarias entre sí que abarcaban la totalidad del hecho, sin distinguir aspectos fácticos independientes que podian haber sido objeto de afirmaciones no necesariamente coincidentes apoyadas en contraindicios. Mas insistamos en que ello no es 
admisible dado que no puede sustituirse el criterio delTribunal de instancia en la labor de valoración de la prueba sobre el indicio, cuando tal valoración depende del nunca suficientemente ponderado principio de inmediación. Que fue verificado ante los ciudadanos-jueces, y no en otra instancia. Entiende el Tribunal Supremo, y nos sumamos a su apreciación, que la inferencia realizada por el Tribunal del Jurado que presenció directamente la prueba, oyó las explicaciones del acusado, las manifestaciones de los testigos y los informes de los peritos, no se ve desvirtuada por la existencia de otros datos objetivos, y en tanto que los jueces legos se ajustan en su proceder a las reglas de la lógica - lo que descarta toda arbitrariedad-, no puede ser sustituida por otra inferencia, por más razonable que pudiera presentarse en la nueva resolución del caso ofrecida por un Tribunal Superior.

Otro ejemplo de las reticencias manifestadas por los órganos representativos de las profesiones jurisdiccionales frente al Jurado, viene dado por el caso en que una sentencia del Supremo, de la que fue ponente el magistrado Carlos Granados, rechaza los argumentos del máximo Tribunal territorial catalán y confirma punto por punto las apreciaciones de la sentencia dictada en primera instancia que era congruente con el veredicto del Tribunal del Jurado. Es decir, en este último caso vemos como el Tribunal Supremo da la razón a un Jurado popular frente al criterio del Tribunal Superior de Justicia de Cataluña ante un delito de asesinato. Para este supuesto contemplamos como el Tribunal Supremo anula la sentencia del Tribunal Superior de Justicia de Cataluña que en su instancia rebajó en siete años la pena impuesta por entender que no se produjo ensañamiento ni alevosía; circunstancias ambas que sí fueron apreciadas por los jueces legos catalanes y que los jueces profesionales eliminaron en su resolución enmendando la plana indebidamente a los jurados, según estimó de nuevo el Tribunal Supremo. Concluyamos, pues, que esa tendencia evidenciada en apelación y que denotan los jueces técnicos, consistente básicamente en sustituir los criterios valorativos probatorios operados por los ciudadanos jurados, es una manifestación clara de qué consideración merece a aquéllos el Tribunal del Jurado.

III

No es el momento ya de plantear arteras preguntas en torno al anclaje del modelo institucional puro de Tribunal de Jurado por el que ha optado la ley vigente, porque ello nos llevaría a caer en la tentación 
de reconstruir rancios episodios decimonónicos que se han revelado poco recomendables para la permanencia constitucional del Estado. Por encima de concepciones pro o antijuradistas, estamos constatando que la traditio constitucional nos ofrece un instrumento indiscutiblemente participativo. Al respecto conviene tener presentes los atinados pronunciamientos del profesor Lorca Navarrete, en particular, los referidos al modelo que él mismo llama de juradismo frente al escabinadismo. El propio Lorca Navarrete nos advertía en el número 2 del año 2000 de la Revista Vasca de Derecho Procesal y Arbitraje, de las pretensiones urdidas en esta legislatura a favor del escabinadismo, dando así al traste con un hito clave en la historia del proceso penal español. En este punto coincide el Informe 2002 de la Fiscalía General del Estado acerca de la experiencia aplicativa del Jurado y algunas propuestas de reforma, ya que considera al Tribunal del Jurado como un propósito legislativo de inflexión histórica con los criterios que hasta 1995 venían presidiendo el enjuiciamiento penal. El contenido de los artículos 24, 117 y 120 de la Constitución, entre otros, dan estribos interpretativos suficientes de cuanto estamos diciendo y ello, particularmente, en sintonía con la evolución sufrida por los procedimientos criminales definitivamente apoyados sobre el principio acusatorio y las garantías procesales de raíz constitucional. De cuya conformidad, dicho sea de paso, es expresión la anunciada e inminente reforma de la Ley rituaria criminal.

Tras veinticinco años de construcción constitucional y casi nueve de implantación del Tribunal del Jurado, encontramos una institución histórica rejuvenecida pese a su vetusta procedencia, que se erige como modalidad singular del ejercicio del derecho subjetivo a participar en los asuntos públicos, que se incardina nítidamente en la esfera perteneciente al status activae civitatis. Nos encontramos con que el Tribunal del Jurado ha sabido implementar el derecho subjetivo a participar en los asuntos públicos, no a través de intermediarios o representantes cualificados, sino ejercitado directa y personalmente mediante el acceso del ciudadano a la condición de juez lego. Ello entra en conexión directa con la afirmación precedente relativa a la permanente crisis de legitimación del Poder Judicial. Puesto que la fórmula que hemos dejado apuntada condensa la idea de que ya no corresponde, únicamente y en exclusiva, a una casta de expertos e iniciados la administración de lo que la sociedad considera justo. En este sentido creo que a estas alturas a pocos se ocultará que la obligada presencia de mediadores profesionales cualificados entre el hombre de la calle y el orden legal establecido, genera cuantitativos y cualitativos quebrantos ciudadanos, y hasta ciertas crisis constitucionales $o$ 
de credibilidad colectiva de los destinatarios en el sistema. Si se me permite la expresión, diría que franquear la cocina de la Administración de Justicia a los ciudadanos revestidos de jurisdicción caso a caso, creo que está resultando más que positivo en los términos expuestos. Baste indicar en relación con todo ello la apuesta por el sincretismo procesual por el que opta abiertamente desde el año 2000 la vigente Ley de Enjuiciamiento Civil.

Por razones obvias no voy a aludir aquí a los rigores punitivos que también podemos extraer del funcionamiento de la institución, precisamente en un momento específico de la natural oscilación pendular que supone la variabilidad de criterios en materia de política criminal. Lo cierto es que el Tribunal del Jurado es mucho más duro, en términos punitivos, que el juez técnico. Los datos consultados arrojan cifras elocuentes que alcanzan un cincuenta por ciento más de rigor sancionador en veredictos pronunciados por ciudadanos-jueces que por jueces profesionales. De otro lado las encuestas apuntan en la misma dirección, eso si, cuando lo que se pregunta a la ciudadanía versa sobre sus preferencias personales ante la eventualidad de un enjuiciamiento criminal que recaiga sobre el propio interrogado. La misma ratio se dispara hasta rozar el cien por cien cuando la cuestión se plantea a la población reclusa (fuente: Juzgado de Vigilancia Penitenciaria núm. 9 de Andalucía - Jaén-, durante mi prestación de servicios en el mismo en el año 2000).

La racionalidad ética de cuanto se señala nos ha de conducir al análisis sosegado de la institución del Jurado en un espectro territorial (provincial) determinado que nos sirva, si es posible, para sacar un puñado de conclusiones. De ahi que hayamos decidido centrar la lupa y el bisturí en torno a lo acontecido, en términos jurídicos y procesales, sobre el Jurado en la demarcación judicial de la Audiencia Provincial de Jaén durante los últimos años. Ello no significa pasar por alto, por ejemplo, la valoraciones que el Tribunal del Jurado ha merecido en la Comunidad Valenciana (Elisa Alfaro, Santiago Real, Mercedes Novo), donde al parecer se ha producido una ralentización y encarecimiento de la actividad judicial concatenada. En ese análisis cercano que proponemos los datos consultados procedentes de la Fiscalía de la Audiencia Provincial de Jaén arrojan las siguientes cifras: a 15 de marzo de 1996, se constata que no se ha incoado ningún procedimiento ante el Tribunal del Jurado desde la aprobación y entrada en vigor de la Ley y el 31 de diciembre del mismo año. A 21 de marzo de 1997, se constata la incoación de dos procedimientos ante el Tribunal del Jurado entre uno de enero de 1996 y 31 de diciembre del mismo año, sin que en dicho ejercicio tuviera lugar vista oral alguna al efec- 
to y tampoco, consiguientemente, veredicto alguno. A 10 de marzo de 1998 , comprobamos como la institución empieza a desplegar su potencial, de manera que entre el primero de enero de 1997 y el 31 de diciembre del mismo año se incoan nueve procedimientos penales ante elTribunal del Jurado, de los cuales dos corresponden a los pendientes o incoados el año anterior, y de los siete restantes correspondientes al año 1997 uno de ellos queda sobreseido y archivado, sin que todavía encontremos sentencias dictadas en sentido alguno. A 20 de febrero de 1999, constatamos que entre el uno de enero de 1998 y el 31 de diciembre del mismo año aparecen incoados dieciséis procedimientos ante el Tribunal del Jurado, de los cuales nueve corresponden a los pendientes e incoados en el año anterior, y cinco procedimientos quedan pendientes a 31 de diciembre de 1998. De los dieciséis reseñados, cuatro acaban sobreseidos o archivados, se celebran dos juicios durante dicho ejercicio de 1998, se dictan cinco sentencias condenatorias por conformidad y dos sentencias condenatorias tras vista oral en las que se contradice el criterio del fiscal, no se dicta ninguna sentencia absolutoria del total de siete sentencias dictadas ese año. Efectivamente en 1998 se recurre una sentencia con veredicto condenatorio del Jurado que vista en apelación resulta confirmada por el Tribunal revisor, sin que haya lugar a casación alguna de ésta ni de las demás condenas impuestas por los jueces legos. A 3 de marzo del año 2000, comprobamos que se han incoado entre el uno de enero de 1999 y el 31 de diciembre del mismo año, por un lado, cinco procedimientos ante el Tribunal del Jurado que corresponden a los pendientes e incoados el año anterior, siete procedimientos más ante el Jurado ventilados en dicho ejercicio 1999, de los que se celebraron seis juicios, se dictaron seis sentencias condenatorias, dos por conformidad y cuatro condenas de acuerdo con la acusación fiscal. Por tanto, en 1999 se celebran seis juicios y se dictan seis sentencias condenatorias; el porcentaje es bastante elocuente, del cien por cien de condenas sea como fuere la forma de solventar la causa enjuiciada por jurados. En dicho año 1999, no se presenta impugnación alguna a tales resoluciones condenatorias. Finalmente añadir que en 1999 quedan pendientes otros seis procedimientos ante el Tribunal del Jurado cuyo acto de vista oral no se pudo llevar a cabo en el mismo periplo. Ya en el año 2000 aparecen incoados entre el uno de enero y el 31 de diciembre un total de nueve procedimientos ante el Tribunal del Jurado, de los cuales uno es sobreseido y archivado, se celebran cinco juicios y se dictan cinco sentencias condenatorias, tres de conformidad con el fiscal y dos en disconformidad con el acusador público. Tampoco en el año 2000 las partes procesales hacen valer la posibilidad de recursos contra dichos 
veredictos condenatorios. En el ejercicio de 2000 quedaron pendientes un total de nueve causas. En el año 2001, comprobamos que se incoan entre el uno de enero y el 31 de diciembre, por un lado, siete causas incoadas y ventiladas en el mismo ejercicio, de las cuales una fue sobreseida y archivada, se celebraron ocho juicios con una sola sentencia absolutoria - conforme a lo solicitado por el fiscal-y siete sentencias condenatorias, de los siete pronunciamientos condenatorios habidos en 2001, una condena fue por conformidad y seis con arreglo a la petición fiscal. Del total de ocho juicios ante el Jurado celebrados en dicha anualidad, sólo se interpusieron dos recursos y ambos de apelación, con distinta suerte, una apelación resultó estimada y provocó la revocación de la sentencia a quo dictada por el Jurado, y la otra apelación resultó infructuosa debido a que elTribunal Superior de Justicia de Andalucía confirmó la sentencia de instancia popular. En el año 2001 quedaron pendientes un total de ocho procedimientos más ante el Jurado. A 20 de febrero de 2003, constatamos que en el ejercicio de 2002, entre el uno de enero y el 31 de diciembre de 2002 fueron incoados catorce procedimientos ante el Tribunal del Jurado de la Audiencia Provincial de Jaén, de los cuales dos fueron sobreseidos y archivados, se celebraron ocho juicios ante los jueces legos, de los cuales siete fueron sentencias condenatorias, repartidas en cuatro condenas por conformidad, una con arreglo a la petición fiscal y una más condenatoria en disconformidad con el acusador público. Por tanto, en el año 2002 se produjo un único veredicto exculpatorio que dio lugar a una sentencia absolutoria del total de los ocho juicios celebrados ante ciudadanos-jueces. En 2002 sólo en un caso se ejercitó la facultad impugnatoria del conjunto de los ocho pronunciamientos recogidos, $y$ el resultado del recurso de apelación fue confirmatorio del criterio expresado en su instancia por el Tribunal del Jurado. A estos efectos puede ser interesante recobrar el itinerario y saldo procesal del caso que más arriba reseñábamos como ocurrido en el partido judicial de Linares, relativo al homicidio actuado por el marido en la persona de su cónyuge con simulación de accidente de tráfico. En dicho caso la sentencia condenatoria del Tribunal del Jurado se dictó en la ciudad de Jaén el 26 de abril de 2001, y la sentencia revisora dictada en apelación por la Sala de lo Civil y lo Penal del Tribunal Superior de Justicia de Andalucía se emitió en Granada a 11 de julio de 2001, -tengamos en cuenta que la sentencia ad quem de Granada estimaba el recurso de apelación interpuesto por el acusado que resultó condenado por los jueces legos, con la consiguiente revocación del veredicto popular-, y que, a su vez, esta última resolución del Tribunal Superior de Justicia de Andalucía fue objeto de impugnación casacio- 
nal ante la Sala Segunda del Tribunal Supremo, que en fecha 28 de noviembre de 2002 pronunció una resolución estimatoria de la casación interpuesta por la acusación particular del caso contra la sentencia del Tribunal Superior territorial andaluz. Así el Tribunal Supremo recomponía las cosas casando y anulando la referida sentencia con la consiguiente restauración del veredicto condenatorio emitido por los ciudadanos-jueces en Jaén. Dado que no queremos ser profusos, hasta aquí algunos datos empíricos que ofrecemos al análisis del lector para que juzgue por sí mismo la evolución parcelada de la institución.

Cierto es que la bondad ética y la filiación constitucional de una ley no representa, en sí misma, garantía alguna de su eficacia normativa. Por ello precisamente nos ha parecido oportuno realizar una cata investigadora delimitada en el tiempo, el territorio y por supuesto en la materia. Sólo desde el análisis que nos proporciona un muestreo contrastado y proporcional podremos extraer conclusiones verosímiles $y$ aproximadas relativas a la eficacia normativa externa de la institución del Jurado, y evitar así indeseables prejuicios y precipitaciones.

\section{IV}

Por todo ello consideramos que no es una cuestión baladí la relativa a la consolidación del Jurado en España, acabado ya el tiempo de los aspavientos, las efusiones y el efectismo en torno a una institución de tan marcada impronta constitucional como hemos querido manifestar en la líneas que preceden. Finalmente, cualquier reforma del Jurado que se quiera acometer, debe estar capitaneada por la consolidación del marco procesal que haga realidad los principios constitucionales, procesales y exegéticos puestos en juego. En este punto bien se pudiera reflejar que, en efecto, la Ley del Jurado hoy vigente pudo adoptar como modelo alguno de los procedimientos penales contemplados en nuestra vetusta ley rituaria criminal, con aquellas modificaciones que lógicamente fueran precisas atendiendo a la especial naturaleza del proceso ante el Jurado. Pero entre sus virtudes cabe señalar ahora que se adelantaba a la que ya parece inminente reforma procesal del enjuiciamiento criminal en España. Ello supuso que ya en 1995 la Ley del Jurado hiciera suyos buena parte de los postulados y criterios que al respecto había emanado la jurisprudencia del Tribunal Supremo, del Tribunal Constitucional, en especial la STC de 15 de noviembre de 1990, y también del Tribunal Europeo de Derechos Hu- 
manos. Así hemos podido constatar que la vista oral ante los jueces legos reviste unas características singulares que realzan la fase de enjuiciamiento en detrimento de la instrucción sumarial, y ello contraviene el espíritu de la todavía vigente Ley de ritos penales. Aparte de lo dicho más arriba sobre criterios sentados por el Tribunal Supremo, y también como efectos de ello puede ser interesante retener la opinión cualificada de la Fiscalía de Palencia, recogida en el Informe 2002 de la Fiscalía General del Estado acerca de la experiencia aplicativa del Jurado: "...la primera experiencia en la aplicación de la Ley del Tribunal del Jurado ha sido plenamente satisfactoria, hasta el punto de dejar claro que la justicia administrada por los ciudadanos resulta de igual o superior calidad que la producida por jueces profesionales. Es decir, nuestro Jurado ha producido la necesaria potenciación del principio acusatorio, en contraposición al matiz inquisitorial que todavía campa a sus anchas por el más ordinario de nuestros procedimientos penales: el Procedimiento Abreviado. Los valores procesales de inspiración constitucional a los que para acabar nos estamos refiriendo, suponen que de un formal sistema acusatorio mixto, pasamos a un proceso en el cual las partes acusadoras alcanzan un especial protagonismo y deber de diligencia, reforzando de paso la imparcialidad judicial de la que suelen hacer gala los jueces legos. En definitiva, como indicaba el fiscal Montero Juanes, el éxito o fracaso del Jurado en España no deberá venir deducido de actuaciones concretas y puntuales de la institución, sino de nuestra capacidad de extraer lo que de estimulante tiene la vigente norma reguladora delTribunal del Jurado, y asumirlo como parámetro de actuación en toda la jurisdicción penal. Tras lo dicho vemos como al margen del cumplimiento del mandato constitucional, el Jurado explicita en nuestro ordenamiento jurídico determinadas novedades que habrán de irse generalizando en los demás procedimientos penales, siempre precisados de las mayores garantías por la entidad de los bienes jurídicos y valores constitucionales que con ellos se ponen en juego para el justiciable. 